\title{
Language Maintenance and Transmission:
}

\section{The Case of Egyptian Arabic in Durham, UK}

\author{
Yasser A. Gomaa \\ Faculty of Arts, Assiut University, Egypt \\ E-mail: gomaa@aun.edu.eg
}

\begin{abstract}
This sociolinguistic micro-level study examines experiences of five Egyptian families, living in Durham, UK, who are trying to transmit Egyptian Arabic to their children. It provides a qualitative description on the process of Egyptian Arabic maintenance and transmission at the family level. Based on in-depth semi-structured interviews and participant observation, the study explores: how these language-minority families describe barriers to and supports for passing on Egyptian Arabic to their children; the language decisions they make to fulfill their roles; how such decisions are linked to their identity as Egyptians living in an English-dominant country; and the factors that helps their children to preserve Egyptian Arabic. The findings show that the participants regard Egyptian Arabic as a cultural core value that is linked with other core values as religion and identity. Consequently, a number of language-related decisions have been made and implemented to improve their children's Egyptian Arabic spoken proficiency level.
\end{abstract}

Keywords: Egyptian Arabic, Language maintenance, Language transmission, Durham, UK

\section{Introduction}

Egyptian students studying in Durham, a city in the North East of England, are members of a linguistic minority group, interacting with a more powerful linguistic majority group which is culturally and linguistically different. Such perceived cultural and linguistic differences could easily threaten the cultural continuity of those Egyptians. In this regard the continuity and transmission of the Egyptian Arabic Dialect (henceforth EA), which is one of the obvious markers of the Egyptian cultural identity, represents one of the major challenges faced by the Egyptian students' families in Durham. Children of those students are increasingly exposed to English, the majority language in host society, through schooling and peer-interaction. They start shifting to English. Therefore, these families are engaged in a two-front struggle and face particular issues and challenges when transmitting EA to their children. They seek to transmit their non-standard home spoken variety of Arabic or Al-'Amiyyah, the Low variety that is allocated to informal communicative functions such as everyday household conversation, to their children.

The overriding aim of this micro-level study is to provide qualitative description on the process of EA maintenance and transmission at the family level, given the central importance of the family as a site of language transmission. It focuses on the language-related experiences and perspectives of five Egyptian families of the process of transmitting EA to their children. The significance of the current study lies in the fact that such micro-level studies are still relatively scarce, and there is a lack in "theoretical explanations for language maintenance outcomes on the micro or family level" (Tuominen, 1999, p. 61).

The current study addresses the following research questions: How do these language-minority families describe barriers to and supports for passing on EA to their children? What are the factors that help their children to preserve EA? What language decisions they make in order to fulfill their roles? How such decisions are linked to their identity as Egyptians living in an English-dominant country?

\section{Language maintenance as a field of research}

Many researchers attempt to identify the factors that are responsible for the differences in the rates of language maintenance and transmission among different minority groups. For example, Sanchez-Castro and Gil (2008) attempt to explore language maintenance in two different Spanish-speaking communities, the newly arrived Salvadorian community in Queensland, and South Australia's more established Spanish community. They conclude that the Spanish language is currently well maintained in the Salvadorian community because of many reasons that include (1) recency of arrival; (2) reasons for migrating; (3) trips to El Salvador; (4) ongoing contact 
with friends and relatives in El Salvador and concentration of Salvadorians; (5) the use of Spanish in a number of domains (e.g., the home, with relatives and Hispanic strangers); and (6) positive attitudes towards Spanish as a symbol of the community's culture and identity, and as a means of communication. In addition, they find that Endogamous marriages, close links with Spain, and the Spanish community in South Australia are among the facilitative factors of their language maintenance. Furthermore, their study makes it clear that the first generation transmits the Spanish language to the second generation by means of their use of Spanish only at home and by encouraging as well as supporting the integration of their children in the Spanish community.

Similarly, Takeuchi (2008) provides descriptive accounts of five families who were trying to transmit Japanese to their children in Australia. She concludes that using appropriate techniques, such as from books and seminars, ongoing support from cross-language family networks, as well as professional advice to continue native language transmission helped Japanese parents in the process of passing Japanese down to their children. In addition, she suggests that parents need to be prepared to reassess their children's progress and to modify and expand their strategies when the children's preference to use English increases.

In addition, Fishman (1991) designs a model of 'reversing language shift', which diagnoses the difficulties encountered in maintaining minority languages and suggests means to improve this situation. In this model, Fishman (1991, p. 87) presents a "Graded Intergenerational Disruption Scale", which consists of eight stages, each of which is a step towards reversing language shift. On this scale, the higher the rating is the lower the expectations of the language continuity of the group are. Stages four to one involve, as Fishman (1991, p. 401) observes, "Increased power-sharing" rather than diglossia. Stages eight to five are concerned with assigning particular functions to transmit the community language intergenerationally.

Also, Fishman, Gertner, Lowy, and Milan (1985) attempt to predict the relative survival rates of non-English languages in the United States. They provide three criteria according to which a minority language can survive. These criteria include (1) "adjusted claimants"; (2) "institutional" criterion; and (3) a compromise between the two reflecting both number of claimants and ratio of institutions to claimants. According to the three criteria (1, 2 and 3 respectively), the top surviving languages in Fishman's data are: (1) Spanish, Italian, French and German; (2) Hebrew, Korean, Albanian and (3) Thai/Lao; Spanish, Hebrew, German and Polish.

Moreover, based on the immigrant situation in America, Conklin and Lourie (1983) provide some other factors promoting language maintenance including: (1) demographic and social factors (e.g. high concentration, geographical proximity and ease of travel to homeland, and low permanence of residence), (2) cultural factors (e.g., prevalent of minority language institutions, the importance of the minority language in performing religious ceremonies, and the emotional attachment to the minority language as a defining characteristic of ethnicity), and (3) linguistic factors (e.g., the minority language is standard written variety, the use of Latin script in the minority language).

In addition, Smolicz (1981) states that it is very important for the minority group, in order to maintain their home language, to have a number of cultural core values. These values are crucial to its language's existence and continuity. Accordingly, as language is a cultural core value for Greeks and Poles, they are more likely to preserve their language in a minority situation. On the contrary, language is not a cultural core value for the Dutch, who lose their language in similar situations.

Furthermore, Kolss (1966), based on the American immigrant situation, particularly German-English language contact, identifies many factors promoting language maintenance such as: (1) membership of a denomination with parochial schools, (2) higher educational level, (3) being numerically strong, (3) the linguistic and cultural distance from the dominant group, and (4) the attitude of the majority to language or group.

\section{Arabic language maintenance as a field of research}

Many studies attempt to investigate Arabic language maintenance. A number of researchers have been concerned with the minority languages' maintenance in immigrant situations. For example, Clyne and Kipp (1999), who investigate the maintenance of three Pluricentric languages in Australia, have studied the minority languages in Australia: Spanish, Arabic, and Chinese. In their study on the Arabic community in Melbourne, Australia, Clyne and Kipp (1999, pp. 137-216) report that one of the determining factors for the use of Arabic among Arab Australians, especially Muslims, may be related to their religious affiliation since the Quran and Classical Arabic are essential to Muslims. Thus, even in families with Muslim Arab father and non-Muslim, non-Arab mothers, the children and the mothers had learnt to speak Arabic well. Their study indicates that the motivations for maintaining Arabic among Muslims in Australia are: (1) access to the Quran, (2) communication with family members, (3) visits to home country, and (4) the fact that the Arabs in Australia have Arabic schools, in which children learn Arabic, and (4) Arabic-language broadcast on the government multilingual radio station. 


\section{Methodology}

Data were collected by means of in-depth semi-structured interviews conducted by the researcher. All the interviews, conducted in (EA) according to the participants' choice, were audio taped and later qualitatively analyzed. Hamers and Blanc (1989) and Edwards (1994) point out that the core of language transmission, maintenance is the family, and that native language transmission is facilitated by mechanisms that have positive attitudes towards one's own ethnic heritage. Therefore, the participants were five Egyptian families with at least one school-aged child. They have been living in Durham for two to four years. Table 1 gives information about these families. In these families, the researcher interviewed the father, but in a few cases, he interviewed the mother. Most of the interviews took place in a friendly atmosphere since the researcher has good relations with most of the participants.

Being a member of the Egyptian community in Durham, the researcher managed to do participant observation in two families in different domains. He spent nearly three hours in each family; i.e., with the father and children, starting from bringing children from school with the father, then having lunch together at home, and then playing and speaking with the children. During these hours, the researcher was observing the language used for communication between the fathers and children. Moreover, the researcher talked and played with children in order to see whether they can speak and understand EA. He also accompanied these fathers many times at mosque, at university, with friends, and when shopping.

One week prior to the interview date, each participant received a Participant Information Sheet outlining the purpose of the study and a brief procedural explanation of the interview. In addition, each participant was requested to sign a Consent Form to take part in the study. Participants were informed that they were granted anonymity and that their data could be withdrawn from the project at their discretion anytime they wished. It is noteworthy here that a masking of descriptive data, which might identify individual families, has also been undertaken. Soon after, each participant was contacted by telephone to decide a convenient time and a place for the interview. Some interviews took place at the researcher's house. Others took place in the participants' house.

The interview questions elicited participants' views about various topics to do with the maintenance and transmission of EA including: the family's living conditions, such as number and age of family members in the household as well as the family's sociolinguistic data, such as birth data, religion, arrival dates, level of education, and language of education, goals for the transmission of EA, language attitudes and strategies to achieve those goals, children's language exposure, proficiency and choices, and the relationship between EA maintenance and identity.

Moreover, the interview questions included all kinds of questions related to language use within and outside the family, including language choice, code switching, interaction patterns, accessible printed, audio and video material in different languages in the home, children's free-time activities, their participation in mother tongue instruction, and visits to Arabic-speaking areas. This part of the interview was devoted the most time. All quotes by the participants have been translated from Arabic to English by the researcher. Salient themes and patterns relevant to the focus of the study were coded and categorized and will be presented and discussed in the following sections.

\section{Findings and Discussion}

This section presents and discusses the major themes articulated by the participants. These themes depict how Egyptian minority families perceive the process of maintaining and transmitting EA to their children. The information obtained from the interviews is mostly consistent among all the families. The analysis of the collected data reveals that the participants share a strong preference for the transmission of EA to their children, and make efforts to facilitate EA maintenance.

\subsection{Participants' attitudes towards English}

All the participants expressed the importance of having adequate English command for their children's well-being in Durham. In addition, the participants are aware of the various benefits of bilingualism, which is defined by Weinreich (1966, p.1) as "the practice of alternately using two languages", for their children's intellectual development. They believe that bilingualism allows the possibility to look at the world from two different perspectives, thus enhancing one understands of the world and its different cultures. For example, one of the participants says, "learning English will have enormous benefits for my children and it will develop my children's intellectual abilities". Another participant comments that developing his children English language skills is "an investment" in education, and he expresses a strong desire for his children to learn English. In addition, the participants report that, concerning global economy, their children can use English in a future 
profession. The consensus towards bilingualism among the study's participants can be summed up by a phrase from one participant: 'The more languages you speak, the smarter you are'. Therefore, when their children are three years old, the participants enrolled them at Framwellgate Moor School in Durham, where they spend about seven hours a day, and are assisted by their teachers in order to develop their English speaking proficiency. Unsurprisingly, the children were gradually becoming proficient users of English because of their English-only mainstream instruction and the influence of the English dominant environment. The participants expressed their happiness and satisfaction with the fact that their children's English skills has been well taken care of by the school. As reported by the majority of participants, their children's English spoken proficiency level has improved. One of the participants said:

I feel very happy that my son speaks good English now. He is not English proficient like his peers at school, but he knows enough English to function properly in the society. It is easier for him to use English with his friends in school. Amazingly, he is now a Facebook user. He uses it for social networking with his friends and classmates.

\subsection{Participants' attitudes towards transmission of EA to their children}

The analysis of the collected data reveals that the participants share a strong attitude for the transmission of EA to their children, and make efforts to facilitate EA maintenance. They report that it is very important for them to pass on EA, mentioning various reasons why they wish for their children to maintain their home language. First, they view EA as a means of transmitting their Egyptian culture and traditions, thus encouraging the maintenance of the children's Egyptian identity: 'If you have the language, you can introduce the culture'. Second, the participants believe that the ability to speak EA is also very important because it allows the children to communicate with their grandparents and extended family who reside in Egypt. Egyptians value extended family relationships and, especially, the relationship with grandparents, who play a very important role in childrearing. All the participants' children have grandparents who reside in Egypt and do not know English. Their grandparents visit Durham, often staying for several months at a time to help with childcare. All the participants emphasize the importance of maintaining EA to facilitate communication across generations.

\subsection{Participants' efforts to maintain and pass on EA to their children}

Most of the participants report that their familial efforts have been directed toward the maintenance of EA in order to ensure the improvement of EA spoken proficiency level. Considering the importance of preserving and passing EA on to their children, what specific strategies do these language-minority families employ? First, the interviews make it clear that the implementation and enforcement of EA only at home policy is a common practice among all the families. The participants report that they insist that their children speak EA at home. In this regard, they also emphasize both the role of the mother as a language transmitter and the importance of the father's authority to enforce their home language. For example, when their children talk to them in English, they reply in EA and tell them to speak EA as long as they are at home. They believe their children speak English for quite enough time at their English school; therefore, they must speak EA for quite enough time, as well, to maintain their home language. Another participant mentions that he has noticed that his children sometimes use English with each other at home. So he used to ask them to use Arabic: "I say: use Arabic, use Arabic!" Therefore, they respond to him and shift to EA. He believes that when he is around and they feel his presence they tend to use EA more than English. Commenting on his enforcement of "EA only at home", one of the participants says:

We always use Egyptian Arabic at home. We have a family's house rule that whoever speaks English will not go to Keenan House or the mosque in the weekend. My daughter sometimes comes up to me and says "dad my brother spoke English today" and sometime the opposite occurs; my younger son comes up to me and says, "Dad, my sister spoke English today." So, the children have become more aware of this family rule because they know that there is a punishment. This family rule helps us in the process of passing Egyptian Arabic on to our children.

The researcher believes that "EA only at home rule" is a highly important factor in transmitting EA, hence maintaining it, as it keeps it functional. That is, it continues to be used in daily life. Thus, the children's use of EA at home helps them to maintain it as a medium for communication in the family. Pearson and McGee (1993), Garcia and Otheguy (1988), Resnick (1988), Gaarder (1977), and Hayden, (1966) emphasize the importance of 
using the community language at home. For example, Hayden (1966, p. 198) believes that "the active use of the ethnic mother tongue in the home is primarily responsible for enabling children to attain mastery of it".

It is worth noting here that despite the fact that children are asked to speak EA, certain English words are used at home (e.g. 'homework', 'teacher', 'good boy', 'shoes', 'school', , 'juice', 'milk', 'G.P', 'shopping'). The use of these words, the researcher believes, is due to the participants' strong desire to raise their children bilingually, as they believe that bilingualism, if maintained, could lead to social and economic rewards. The followings are typical examples obtained from the participant observation:

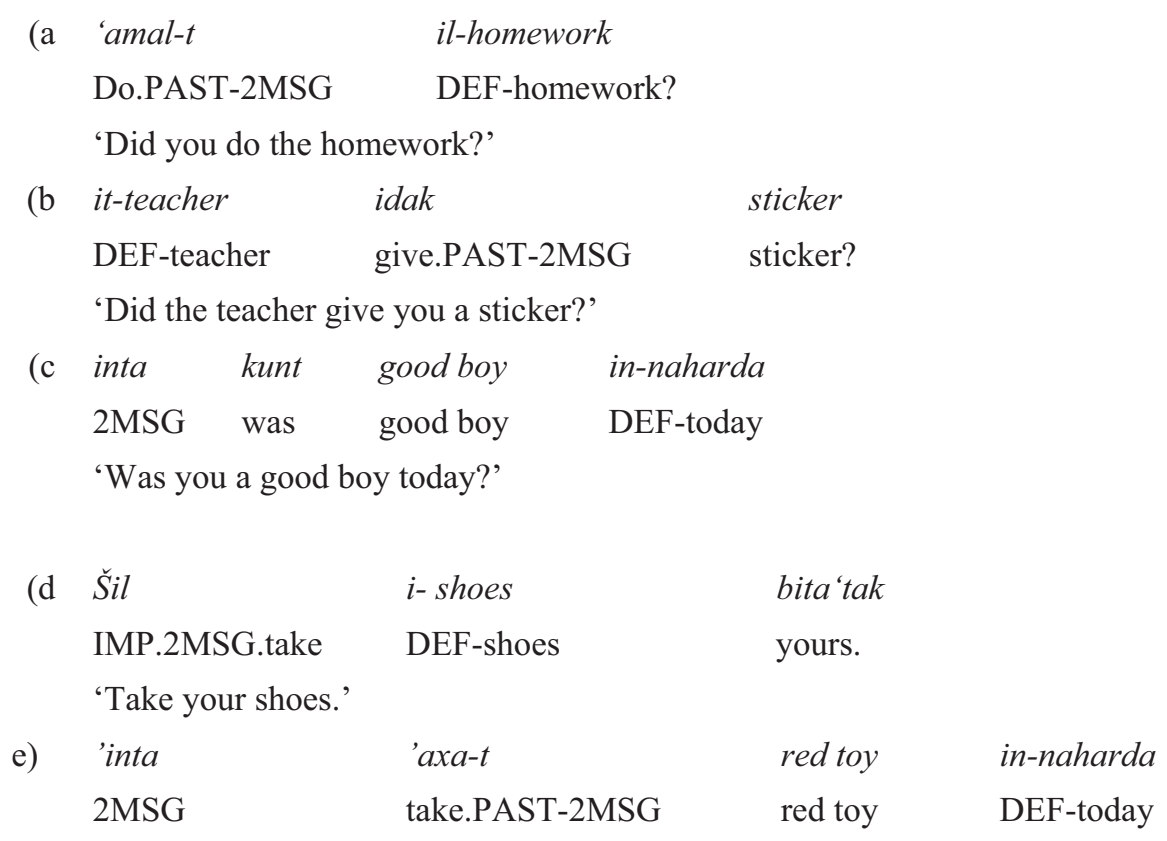

'Did you get a red toy today?'

Second, the participants register their children from the age of six in the Egyptian school in London to study the Egyptian curricula, in which children study Arabic language (i.e., grammar, reading, writing, spelling, etc) that are taught in schools in Egypt. In this case, the children study the Egyptian curricula, which are in Arabic, except for English, Math, and Science, at home and go to London once a year to sit for the exams. The main reason the participants do this is that they are keen that their children learn Arabic. Another reason is that they want their children to study the Arabic curricula that their peers study in Egypt so that they can cope with them when they return home. In addition, at the weekend the participants send their children to Keenan House, Durham University accommodation, where they can play with other Egyptian Children in the common room. In addition, two Egyptian women are volunteered to teach Arabic to the children. The participants believe this is a good chance for their children to improve their EA throughout the communication with EA speaker teachers.

A third way of transmitting EA is through interaction with Egyptian friends and participating in Durham Egyptian Society activities (e.g., Eid ul Fiter's celebration, picnics, journeys, etc.). Often Egyptian families build friendships with each other, exchange visits, and celebrate holidays together. These interactions provide opportunities for children to play with other children who speak EA. The participants report having developed extensive connections with Egyptian friends, some of whom they knew prior to coming to Durham. In general, the participants comment that interaction with other Egyptian families provides opportunities to maintain EA.

As articulated by the three Muslim families, the fourth strategy of transmitting EA is sending the children to Durham University mosque at the weekend; where the children do not learn reading or writing in Arabic, but just learn the Quran. The teaching of Quran at the mosque is in Arabic, and the communication between the teachers and the children is in Arabic. It is noteworthy here that EA is different from "Koranic Arabic", as Fishman (1991, p. 360) describes it, in a striking number of features (e.g., loss of the glottal stop, reduction of inflection categories, increase of symmetry in the grammar). In addition, "Koranic Arabic" is not the vernacular, everyday language of the Egyptian community. However, it remains important in maintaining boundaries between the British culture and the Egyptian culture, a factor which Fishman (1991) considers as the main issue in language maintenance. This is supported by the fact that all Arabs, including Egyptians, regard "Koranic Arabic" as central to the practice of their faith. This belief helps language maintenance exactly as the belief that Armenian is 
the appropriate language of worship helps the maintenance of Armenian language in America and Syria (Saville-Trioke, 1989, p. 205).

The three Egyptian Muslim families consider the mosque as one of the important aids in the process of Arabic language maintenance and transmission. They see it as a good substitute for the Arabic school. They believe it is among their duties as Muslims to pass on the Arabic language to their children because it is the language of the Quran and Muslim daily prayers. In this connection, developing their children's Arabic religious literacy appears to be an important motivating factor that promotes the process of Arabic maintenance and transmission in general and EA in particular. One participant, for example, considers the transmission of Arabic to his children as one of their rights:

Arabic is very important for our children as it is the only medium to read and understand the Quran. It is our role to transmit and teach them Arabic. I believe passing Arabic on to our children is among their rights over us.

As for the two Christian families, they believe it is among their duties as Egyptians to pass on the EA to their children because it reflects their country, and it is a vital element of their children's identity that must be preserved. One of them explains, "Egyptian Arabic represents the most crucial component of our identity as Egyptians". It is clear that the five Egyptian families regard EA as a cultural core value that is linked with other core values such as religion and identity. The term 'cove values' is defined as "values that are regarded as forming the most fundamental components or heartland of a group's culture, and act as identifying values which are symbolic of the group and its membership" (Smolicz and Secombe, 1985, p. 11). Smolicz (1981, p. 77) indicates that, "whenever people feel that there is a direct link between their identity as a group and what they regard as the most crucial and distinguishing element of their culture, the element concerned becomes a core value for the group". Accordingly, a number of language-related decisions have been made and implemented by the participants to ensure the improvement of EA spoken proficiency level among their children.

A fifth way of transmitting EA is through watching Egyptian Satellite Channel (ESC) which features a wealth of television entertainment including variety shows, movies, talk shows, children's programming, etc. The interviews revealed that all the participants are keen on having ESC not only for entertainment but, more important, for maintaining a link with EA, so that their children can maintain and speak it. The information obtained from the interviews and the participant observation indicates that children like to watch Egyptian movies and TV series as they find it interesting. The evidence for this is that one of the participants told the researcher that his children used to ask him about the meaning of many EA words, which they heard in the Egyptian movies, cartoons and TV series. Therefore, the participants mentioned that they always encourage and urge their children to watch the Egyptian Satellite Channel (ESC).

The availability of the Egyptian Satellite Channel (ESC) conforms to Fishman's (1991, p. 105) stage two in his 'reversing language shift' model. It is relevant to the situation of EA maintenance and transmission in the current study. In Fishman's (1991) stage two, the importance of mass media being available in the community language is emphasized. Despite the fact that Fishman talks in this stage about regional and ethnic media being presented in the community language as in the case of Basque (Fishman, 1991, p. 174), we can generalize this to EA media in Durham. Of course, there is no Egyptian TV or newspapers in Durham. However, this is compensated by the fact that ESC is available.

\subsection{How effective are Egyptian families in transmitting EA to their children}

The interviews make it clear that Egyptian children master the use of EA and speak it very well. Evidence for this is that, as the participants said, their children speak EA without making mistakes. They also understand spoken EA; for example, when they listen to a conversation in EA or when they watch Egyptian movies and TV series, they understand what is being said. The researcher noticed this during the participant observation. In the families that he observed at home, he dedicated some time for children. During this time, he was playing and talking about various things: school, friends, parents, toys, etc. He was talking to them only in EA, and they were responding in EA except for some words that they used to say in English (e.g., 'school, teacher, homework, story, book, etc.). This competence in the two languages, along with the parents' instructions, that teach them to use EA at home, and English at school, enable them to make appropriate decisions about the use of one language rather than the other according to the situation (i.e., which language to use, and when). For example, during the participant observation, whenever the children started talking to the researcher, they talked in EA. Thus, since they speak EA with their parents, the children took it by analogy that EA has to be used when talking to older Egyptian people. Furthermore, in one of the interviews when the researcher asked a child whether he speaks 
English all the time at school, he said that when he plays with his friend Omer, another Egyptian child, he speaks EA. It is clear by now that the participants have succeeded to maintain and transmit EA to their children.

In summary, the results obtained from the interviews and participant observation indicates that EA is well maintained and transmitting through the following forms:

a) The higher educational level of the participants that makes them aware of the importance of Arabic in general and EA in particular for their cultural and Islamic identity.

b) The emotional attachment to EA as a defining characteristic of the participants' Egyptian identity.

c) Gatherings, Cultural activities, and the existence of a mosque that plays a significance role in the process of EA maintenance and transmission.

d) The participants' attitude to preserve their Egyptian identity, and their awareness of the linguistic and cultural distance from the dominant group that lead them to exert more efforts in enhancing their EA maintenance and transmission.

e) The permanence of residence in Durham.

f) The participants' efforts to promote EA literacy among their children at home that is consistently encouraged and emphasized by the participants.

g) The availability of the Egyptian Satellite Channel (ESC).

\section{Conclusion}

In this study, the researcher tried to provide a descriptive account of five Egyptian families who were trying to transmit EA to their children in Durham, UK. The factors used in the process of EA maintenance and transmission were investigated. The analysis of the interviews with these families makes it clear that the process of EA maintenance and transmission and involves constant struggle. In addition, it reveals that the participants have shown a strong level of commitment to EA maintenance and transmission. They have an emotional attachment to EA as a defining characteristic of their Egyptian identity. This linguistic and identity awareness led them to exert much efforts to maintain and pass EA on to their children. Moreover, the participants believed that EA transmission to their children as one of their children's rights. Many factors appeared to promote EA maintenance and transmission, such as the higher educational level of the participants (see Table 1). This factor led them to be aware of the importance of Arabic in general and EA in particular for their Egyptian and Islamic identity. Also, using EA consistently at home (either between the parents or between the parents and their children), watching Egyptian Satellite Channel (ESC), together with the association between EA, religion, and identity were very prominent in the data and appeared to be effective motivating factors in favor of EA. All these factors play an important role in maintaining EA as they help the participants in this regard. It remains to say that these factors are most effective when they are combined together However, the researcher believes the most important factor in transmitting and maintaining EA is using it at home since it keeps it continues to be used in daily life.

\section{References}

Clyne, M. and Kipp, S. (1999). Pluricentric languages in an immigrant context: Spanish, Arabic and Chinese. Berlin; New York: Mouton de Gruyter.

Conkline, N. and Lourie, M. (1983). A host of tongues: Language communities in the United States. New York: Free Press.

Edwards, J. (1994). Multilingualism. London: Routledge.

Fishman, J. (1991). Reversing language shift. Clevedon: Multilingual Matters.

Fishman, J., Gertner, M., Lowy, E. and Milan, W. (1985). The rise and fall of the ethnic revival: Perspectives on language and ethnicity. Berlin: Mouton de Gruyter.

Gaarder, A. (1977). Language maintenance or language shift. In W. Mackay and T. Andersson (Eds.), Bilingualism in early childhood. Rowley, MA: Newbury House, pp. 409-434.

Garcia, O. and Otheguy, R. (1988). The language situation of Cuban Americans. In S. Mackay and S. Wong (Eds.), Language diversity: Problem or resource? Rowley, MA: Newbury House, pp.166-192.

Hamers, H. and Blanc, H. (1989). Bilinguality and bilingualism. Cambridge: Cambridge University Press.

Hayden, R. (1966). Some community dynamics of language maintenance. In J. Fishman, V. Nahirny, J. Hofman and R. Hayden (Eds.), Language loyalty And the United States. The Hague: Mouton, pp. 190-205. 
Kloss, H. (1966). German-American language maintenance efforts. In J. Fishman, V. Nahirny, J. Hofman and R. Hayden (Eds.), Language loyalty in the United States. The Hague: Mouton, pp. 206-52.

Pearson, B. and McGee A. (1993). Language choice in Hispanic-background junior high school students in Miami: A 1988 update. In A. Roca and J. Lipski (Eds.), Spanish in the United States. Linguistic contact and diversity. Berlin; New York: Mouton de Gruyter, pp. 91-101.

Resnick, M. (1988). Beyond the ethnic community: Spanish language roles and maintenance in Miami. International Journal of the Sociology of Language, 69: 89-104.

Sanchez, O. \& Gil, A. (2008). Two Perspectives on Language Maintenance: The Salvadorian community in Queensland and the Spanish community in South Australia. The International Journal of Language, Society and Culture, 26 (1), 80-92.

Smolicz J. and Secombe, M. (1985). Community languages, core values and cultural maintenance: The Australian experience with special reference to Greek, Latvian and Polish groups. In Clyne, M. (Ed.), (1985), Australia, meeting place of languages, Canberra, ANU / Pacific Linguistics, pp. 11-38.

Smolicz, J. (1981). Core values and ethnic identity. Ethnic and Racial Studies, 4: 75-90.

Takeuchi, M. (2008). Japanese-English child-rearing practices in Australia. In A. M. Stoke (Ed.), JALT2008 conference proceedings. Tokyo: JALT.

Tuominen, A. (1999). Who decides the home language? A look at multilingual families. International journal of the sociology of language, 140, 59-76.

Table 1. Information about the Five Egyptian Families

\begin{tabular}{|c|c|c|c|c|c|c|}
\hline \multirow[t]{2}{*}{$\begin{array}{l}\text { Family } \\
\text { No. }\end{array}$} & \multirow{2}{*}{$\begin{array}{l}\text { Father's } \\
\text { education/ } \\
\text { occupation }\end{array}$} & \multirow[t]{2}{*}{$\begin{array}{l}\text { Mother's education/ } \\
\text { occupation }\end{array}$} & \multicolumn{2}{|c|}{$\begin{array}{c}\text { Number and age of } \\
\text { children }\end{array}$} & \multirow[t]{2}{*}{ Religion } & \multirow{2}{*}{$\begin{array}{c}\text { Years in } \\
\text { Durham, } \\
\text { UK }\end{array}$} \\
\hline & & & Daughters & sons & & \\
\hline 1 & PhD Student & Bachelor degree & $1(6 \mathrm{Y})$ & $1(4 \mathrm{Y})$ & Christian & 2 \\
\hline 2 & PhD Student & Bachelor degree & $1(4 \mathrm{Y})$ & $1(5 \mathrm{Y})$ & Muslim & 3 \\
\hline 3 & PhD Student & Bachelor degree & $1(9 \mathrm{Y})$ & $1(6 \mathrm{Y})$ & Christian & 4 \\
\hline 4 & Judge & PhD Student & $1(4 \mathrm{Y})$ & $2(9 / 6 \mathrm{Y})$ & Muslim & 4 \\
\hline 5 & $\begin{array}{l}\text { University } \\
\text { Lecturer }\end{array}$ & $\mathrm{PhD}$ Student & 0 & $2(10 / 6 \mathrm{Y})$ & Muslim & 4 \\
\hline
\end{tabular}

Key: The number of daughters/sons is mentioned first, then the age followed by the letter Y (Years old) 